\title{
To Build Open Community and Cluster Closed-unit under the Circumstance of Land Unit Use
}

\author{
Xiaofan Zhao
}

\author{
School of design and art ,Shenyang aerospace university, Shenyang, Liaoning China \\ zhaoxiaofan7724@163.com
}

Corresponding author Xiaofan Zhao

Keywords: land use unit, update mode of land units, open and closed

\begin{abstract}
Reflection on China's residential area. We will see the hierarchical land use model of residential areas--residential unit-housing cluster development. According to present and future needs, we face the problem between transportation and land use in urban area as follows: urban traffic microcirculation problems, lack of urban public space, functional fragmentation isolation, and land use inefficiency. Considering old city renewal we still use outdated and obsolete thinking methods. In the context of green space revitalization in old urban areas, how to deal with the new demand of urban space changes, how to break through the traditional construction methods, how to abandon "the bigger the better" erroneous thinking, how to avoid isolation between land units . how to reduce wasteful and low functional landscape in residential area. We will adapt to sharing, networking, communicating model to reorganize the urban land use units and to shape dynamic streets and places.
\end{abstract}

\section{用地基本单元视角下的开敞社区封闭组团模式建构 \\ 赵晓凡 \\ 沈阳航空航天大学设计艺术学院, 沈阳, 辽宁, 中国 \\ zhaoxiaofan7724@163.com \\ 通讯作者: 赵晓凡}

关键词: 用地单元; 用地单元更新模式; 开敞与封闭

中文摘要. 反思我国居住区一居住小区一居住组团的用地单元模式。针对当下及未发展, 特 别是交通与土地利用的城市问题突显, 城市交通微循环障碍, 城市公共空间缺乏与碎片化, 利用效率不高, 旧城更新改造中的一些思维惯性错误等问题。在城市土地的有机更新背景下, 如何面对城市空间变化的新需求，打破传统的建设模式，摒弃求 “大”的错误思维，摒弃孤 岛, 隔离型土豪世界的城市面貌。通过模式梳理来适应共享, 网络化, 富有活力交往模式空 间。实现街道回归型的城市密集化场所和用地单元重构。

\section{1. 引言}

现代的欧美人, 尤其是青年一代, 几乎分享所有的东西, 孩子的玩具, 汽车, 甚至房子 都可以和陌生人共享。共享有很强的流动性, 一切在共享中完成。一种将是改变我们生活的 新经济范式出现一协作共同体，协作经济正在出现，而交换经济在渐渐走向没落。通过协同 
共享, 以接近免费的方式, 同时分享一系列的商品和服务, 这是最具有生态效益的发展模式, 也是经济可持续的发展模式。【杰里米.里夫金】

要适用于共享经济模式能依据三个标准。其一, 是否能重构体验的颠覆。这种颠覆并非 对原有业务的体验进行改良或放大，而是革命性地产生变化。“不是比原有体验好 $10 \%$ 或者 $50 \%$, 而是比原有体验好 5 倍、10倍。”其二, 是否能重构商业价值。龚炎重点谈到, 整个共 享经济的大前提, 是建立在碎片化时间以及闲置资产。共享模式, 是否能够真正释放碎片化 时间的价值, 是否真正能够释放闲置资产价值是关键。其三，是否能重构连接。连接的方式 以及连接的成本、连接本身的三个纬度上能够彻底重构。

\section{2 目前城市建设阶段性问题}

超级社区作为新的典型城市组成单元体（商品）主宰了城市。它从表面上的特点是同样 划分了人的空间，但是却没有有效的建立其自身的系统。超级社区主要有两个类型：1）坐落 在景观中的塔楼。2）围合景观的板楼。在两种类型当中，公共空间和建筑都缺少城市策略性 一一只是一种商品, 而没有社会效应。容器仅仅容纳。人们的生活更多的发生在容器之外一 即城市中。而这种容器是封闭的而不是共享的。

\section{1匿名化的公共交往空间缺乏, 社区归属感差}

今天人们的生活模式在时间上碎片化，在空间上也体现出强烈的碎片化需求。作为人们 交往公共空间也体现在强烈的碎片化形态, 不同年龄的人群之间的生活是嵌套式的交集空间, 而这种交集空间呈现出匿名化, 小型化, 网络化的特点。私有化的公共空间越来越强烈。而 我们现实的城市公共空间却被挤压到大型的独立单元地块内。不但出行距离远, 而且由于空 间被过度商业化这种大型的公共空间是以消费为导向的空间, 一切非消费的空间被驱逐出公 共空间领域之外。以兴趣, 爱好为基础空间需求被等级化和门槛化。公共性空间实质的公共 性被商业化取代。人们在公共空间内的活动体现为明显的私人性群体特点。而这种私有性也 体现出支离破碎的状态。坐落在城市空间的大型开敞空间斑块就是在这种供给和需求的矛盾 中存在, 居住空间容器与居住空间外的公共空间容器被城市交通型干道联系起来。碎片化的, 匿名的公共空间严重缺乏。而非消费领域的公共空间严重供给不足, 被割裂在一个个所谓居 住小区公共空间内部, 而这种以服务半径和人户口用地规模为基础的配给, 并未实际反映出 人们实际的需求。而这种配给也未被充分利用, 大多情况被闲置下来。问题的核心是规模过 大导致的邻里感变弱。公共空间也没有实质性的公共作用。社区建设必须以建设街道和城市 公共空间为核心，而不是仅仅建花园，这是过去20年来的社区建设的最新发展显示。

\section{2围墙大门形成的一个个居住孤岛, 内部公建设施的绝望与物业维护成本的增加。}

功能混合式一个普遍认识的概念, 问题是功能混合在用地内部还是混合在用地边缘。功 能混合在地块内部以简单的服务半径来配置, 就会产生一个个自成体系的孤岛, 也就是消耗 性闲置型, 缺乏交流型的功能空间。功能混合在边缘就会产生共享, 彼此联系流动的充满活 力的场所。目前以居住小区为代表的用地单元与城市道路衔接上是 2 至 3 个机动车出入口面向 城市次干路和城市支路。在人车分流的小区建设模式下形象入口或步行入口一般情况下面向 城市主干道或次干道。无论何种通路出入口都是被大门封闭的。小区自身配套越是齐全, 小 区之间的关系联系上就越发隔离。在小区内部的公建设施在中国社会中经营往往不善, 废弃 掉。成为没有实际使用意义的形象代言。同时由于小区规模的原因, 物业管理上更加复杂, 维护成本必然增加。在这样一个个孤岛型的小区中, 公建设施没有充分利用, 社区归属感降 低和公共空间闲置。成为公共空间流动共享的障碍。

住宅区规模对住宅区的生活服务设施配建起着重要的作用。十几公顷以上的住宅区往往 要求住宅区自身服务设施比较齐全, 而又因为物业和保安管理的需要对外则用围墙隔离, 往往 
最终形成了封闭式的。就生活服务设施本身来说,随着社会经济的发展现代人普遍讲究生活品 质, 小区内部的配套服务设施因服务规模的限制无论就其规模、服务水平或其提供的设施项目 本身都无法满足居民生活的需要, 因而也难以维持日常的经营, 造成了住宅区内各种设施的低 效能运转,这也就是为什么原先服务小区内部的商店往往养不活自己,纷纷破墙对外开店的原 因之一。

\section{3 城市支路网络截断, 城市干路拥堵, 街道消失}

“住宅小区” 出现后最可怕的后果是，作为城市文明最精华的 “街道” 也就消失了。随着城 市景观中最重要的街景不复存在, 城市的灵魂丧失, 社区感、舒适感和亲切感也全部荡然无 存。人们在城市之中感觉到的就是连接不同小区之间的拥挤嘈杂的 “大马路” 了。现代主的 功能分区和 “住宅小区” 带给城市的绝不仅仅是拥堵的交通和单调的城市景观, 它带来了更 深层次的无法回避的难题, 它带来的是一种功能和效率低下的城市模式, 是一种大量消耗能 源和土地浪费型的城市, 是一种没有社区感不适宜居住型的城市, 是一种破坏文化传统的和 形成文化沙漠的城市模式。它代表了一种浪费型的不可持续的城市模式

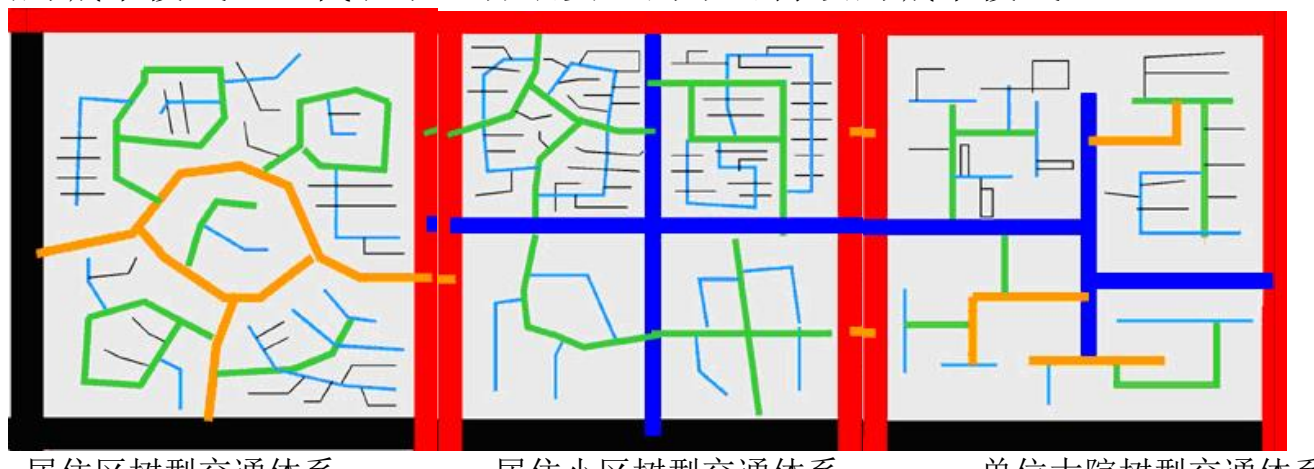

图1 树型交通体系 来源: 作者

\section{4社区土地利用结构呈明显分级的树型}

小区模式等级化的组织结构, 把居住空间机械地分解为住宅、道路、服务设施、绿地等 一系列子系统, 道路宽度、绿地、大型服务设施规模, 根据等级层层分解、逐级缩小, 从而 将各个子系统分解成等级化的 “树形结构” 排除了居住、交通、休闲、服务等空间的综合交 叉, 无法与居发生活的多元性和多样性所上具有的网络化结构相符合, 泯灭了物质形态与社 会网络、人文关系的对应。

从本质上讲，以邻里单位为原型的小区模式忽视了人对居住空间的主体性，单纯注重形 体美学及其特质形体的功能结构。因此当物质环境得以完善、再进而追求居住空间更多的精 神层次内涵的时候, 小区模式就明显地表现出先天不足, 难怪现在有的居住小区中, 人们享 受物质环境日益完善的同时，感慨精神生活的贫痊，居民对所居住的空间缺乏认同，居民缺 乏交往，人际关系冷漠。

“树形结构” 的城市和居住区具有极大限制性, 在这个结构内, 没有一个单元和其他单元相 互连接，它 “把城市的自然特性合理性和必要的重合性给彻底毁灭了。”（如图2）这样的结 构是导致社区性的丧失。1965年克里斯托弗 - 历山大否定了把城市各层次等级一化地看成系 统的 “树形结构” , 根据实际城市生活, 提出了比 “树形结构” 复杂得多的、很多方面交织 在一起的、互相重叠的城市 “半网络结构。” 亚历山大认为: “城市不是, 也不能是, 并且 必须不是树形结构, 城市是生活的容器。假如因为此容器是树形结构, 从而割断了在其间的 生活流的相互交叠, 那么这样的城市就像一个盛满直立刀片的碗一样, 随着准备切断任何交 赋予它的物体……倘若我们建造具有树形结构的城市, 那么, 这种城市将把我们在其间的生 活绞得粉碎。”亚历山大的半网络模型是按城市内在规律, 以系统的观念来进行城市研究的 一个良好起点。 


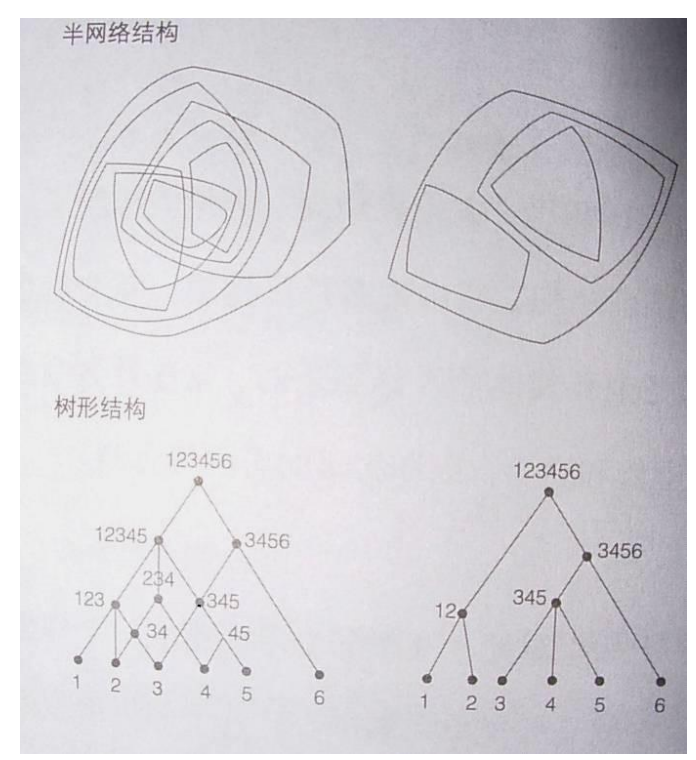

图2 半网络结构与树形结构 来源: 陈劲松 2003,1

半网络结构的 “交迭组织” 由于人与环境双方的 “同化与调节” 作用，且双方作用路径 并不相同，因而在空间上、实践上和心理层次上形成多元 “网络结构”。此概念对应于社区 时, 首先要指出的是任何社区从空间分布上看都是人的集合，其次它也是人们交往的空间。 个体的差异以及社区内各群体的差异决定了社区成员承担社会角色的多样性及社区内外交际 网络的多元化, 单一化或等级化的社区建设将抹杀社区的活力, 也破坏社区的动态平衡, 因 而网络社区概念的提出也就是为了体现出社区多样化发展的要求。我们处心积虑地沿用规划 中的 “以人为本” 的思想, 把小区界限严格区分, 为了每个小区的特别定位客房所设定的配 套和商业服务, 几乎是完全失败的。

\section{3 问题产生的原因}

\section{1居住区设计规范与城市道路交通规范中的冲突}

居住区按规模大小不同分为居住地区、居住区和居住小区3个层次。居住地区由 $3 \sim 5$ 个居 住区组成，居住用地在 $150 \sim 300$ 公顷之间，可建住宅 $150 \sim 300$ 万平方米，可居住人口 $10 \sim 20$ 万人。居住区由 $3 \sim 5$ 个居住小区组成, 居住用地 $40 \sim 60$ 公顷, 可建住宅 $40 \sim 60$ 万平方米, 可 居住人口 $3 \sim 4$ 万人。居住小区由 $4 \sim 5$ 个住宅街坊组团组成, 居住用地 $10 \sim 20$ 公顷, 可建住宅 15 20万平方米, 可居住人口 $1 \sim 1.5$ 万人。（如图3）

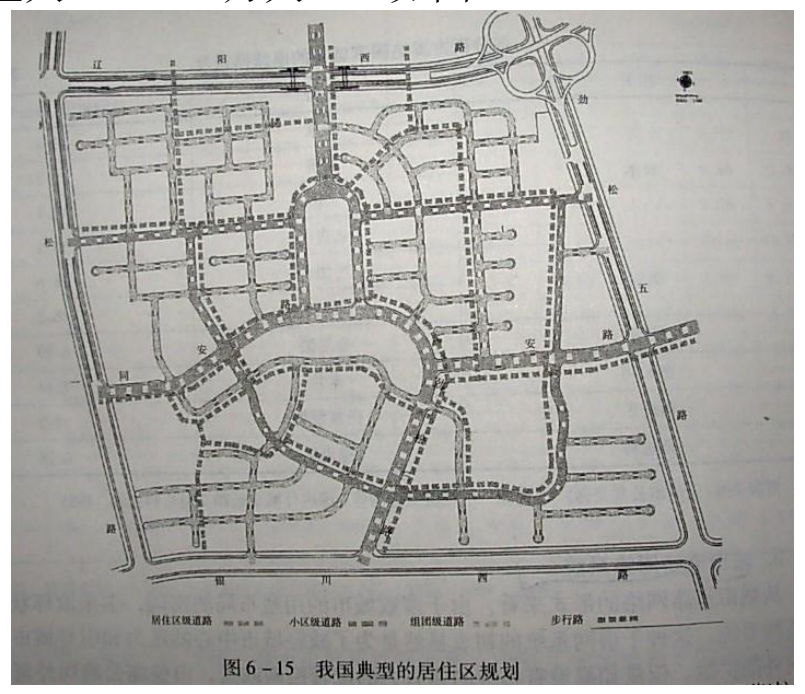

图3我国典型居住区规划 
表一 居住区人口, 用地, 交通规模参考数据

\begin{tabular}{|c|c|c|c|c|c|}
\hline & 居住区 & 居住小区 & 居住组团 & 街坊 & 院落 \\
\hline 数 & 10000-15000户 & 2000-4000户 & 300-700户 & 800-2000户 & 50一-100户 \\
\hline 口 & 30000-50000人 & 7000-16000人 & 1000-3000人 & 2500-6000人 & 150-300人 \\
\hline 占地面积 & 50-100ha & 10-35ha & 4-6ha & 6-10ha & $0.5^{-} 1$ ha \\
\hline 用地单元约 & 1000 米*1000米 & 500 米*500米 & 250 米*250米 & 300 米*300米 & 80 米* 80 米 \\
\hline 内部道路 & 居住区级 & 居住小区级 & 居住组团级 & 街道+宅间 & 宅间 \\
\hline 道路宽度 & $\begin{array}{l}\text { 红线宽度20-30 } \\
\text { 米 }\end{array}$ & $\begin{array}{l}\text { 建筑控制线 } 10-14 \\
\text { 米, 路面宽度6-9米 }\end{array}$ & $\begin{array}{c}\text { 路面宽度 } \\
4-6 \text { 米 } \\
\end{array}$ & $\begin{array}{c}\text { 路面宽度 } \\
4-6 \text { 米 } \\
\end{array}$ & $\begin{array}{l}\text { 路面宽度 } \\
2.5-4 \text { 米 }\end{array}$ \\
\hline
\end{tabular}

表二 城市道路交叉口间距推荐值

\begin{tabular}{|l|l|l|l|l|}
\hline 城市道路类别 & 快速路 & 主干路 & 次干路 & 支路 \\
\hline 设计车速 $(\mathrm{km} / \mathrm{n})$ & $\geqslant 80$ & $40-60$ & 40 & $\leqslant 30$ \\
\hline 交叉口间距 $(\mathrm{m})$ & $1500-2500$ & $700-1200$ & $350-500$ & $150-250$ \\
\hline 道路红线宽度 & $60-100$ 米 & $40-70$ 米 & $30-50$ 米 & $20-30$ 米 \\
\hline 服务地块面积约 & $225 \mathrm{ha}-625 \mathrm{ha}$ & $49 \mathrm{ha}-144 \mathrm{ha}$ & $12 \mathrm{ha}-25 \mathrm{ha}$ & $2 \mathrm{ha}-6 \mathrm{ha}$ \\
\hline
\end{tabular}

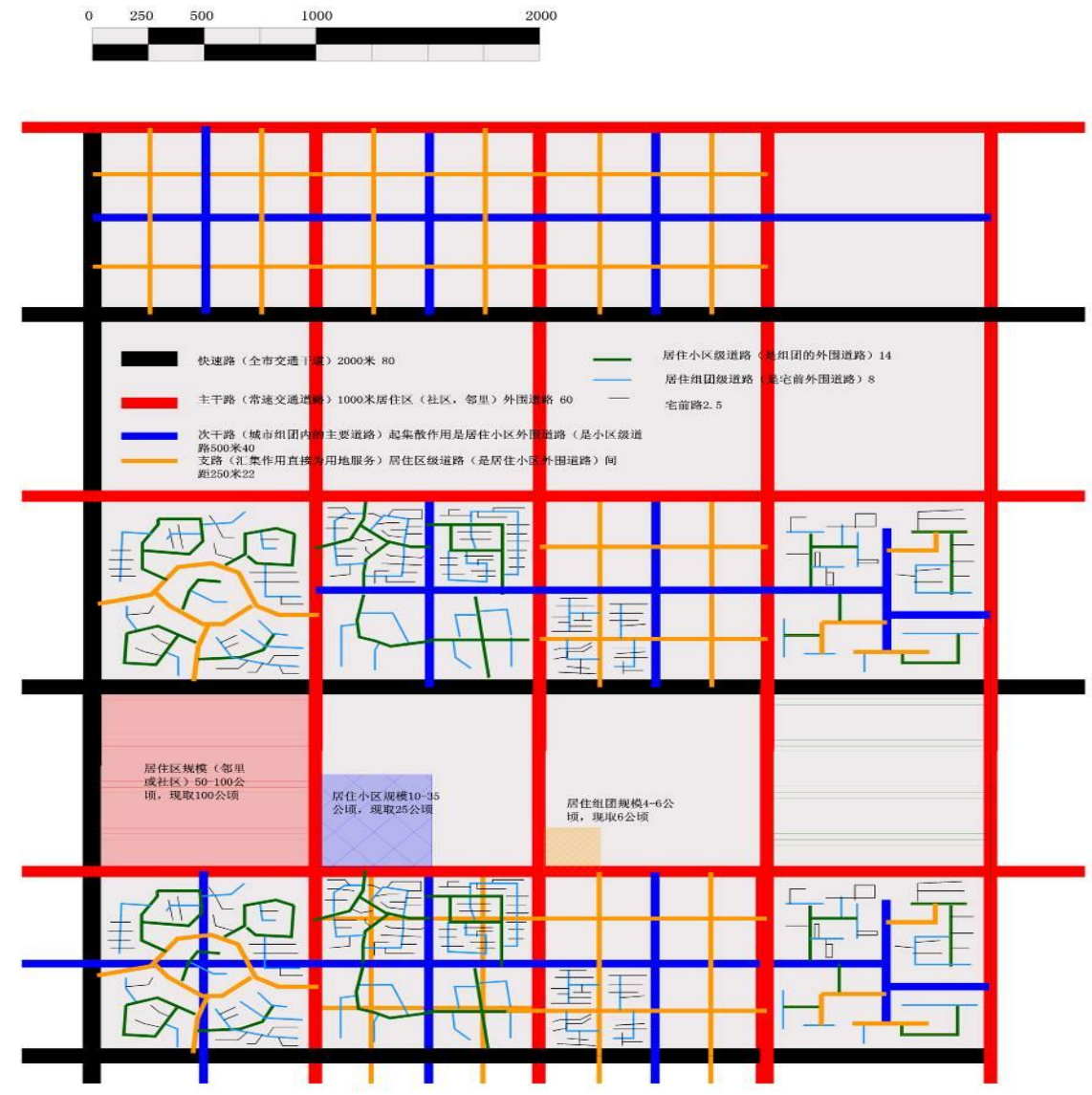

图4 中国城市道路交通规范与城市居住区规范之间的矛盾各成体系 
根据道路设计的规范绘制的理想状态模型, 居住区, 居住小区规划模式及占地面积, 进 行叠加, 我们会发现, 居住区模式以50-100公顷为例, 城市的次干路被居住区级道路所代替, 地块内部城市的支路消失了。以居住小区模式为例10-35公顷左右，小区外围由城市次干路或 城市主干路与次干路共同围合，地块内的城市支路也消失了。如果以组团规模4-6公顷为例建 设的居住单元地块中我们会发现, 城市的次干路, 城市支路同时存在。所以通过两个规范的 叠加, 我们看到各为体系的建设模式有明显的冲突, 次干路问题并不是很明显, 而以居住小 区为基本用地单元的建设模式下，城市支路网被吞噬了。加上封闭小区的建设模式，城市交 通微循环必然不畅通。以城市支路为原型的街道空间随着城市的进一步建设也渐渐消失了。 针对道路宽度而言, 目前在大型居住区规模内应该有城市次干路级别的主要道路（红线宽度 应该在30-50米) 而居住区级道路实际建设只有（红线宽20-30米）这个级别的道路是城市支 路级别。而居住小区用地规模内应该有对于城市道路网的合理性而言, 城市支路级别的主要 道路却被居住小区级道路取代。即被6-9 米的路面宽取代。这种建设模式的直接结果就是, 城市干路网建设及与此链接的羊肠小路的模式。所以居住区, 居住小区分级的地块用地模式 与城市道路网的主干路-次干路-支路 建设模式必然冲突。（如图4）

根据我国《城市居住区规划设计规范》第2.0.8条，居住区（级）道路“在大城市中通常 与 城市支路同级”，这表明，居住小区，居住组团以及居街坊道路等居住区级以下的道路属于 支路以下级道路, 这些道路以出入交通功能为主; 而我大城市支路承担的并非完全是出入交 通, 还兼具较大量的集散交通, 并配置有公交路线, 因此要求我国大城市支路之间需要适当 衔接。与欧美城市不同, 我国城市大多紧凑、连片发展, 居住区是其中的部分, 而非一个个 分散, 独立的郊区居住地块, 如果主要支路采用 “枝状” 或 “错位交叉” 形式, 势必削弱外 部地块的交通条件, 并危及道路网络的整体组织, 因此从 “尽端路” 到目前居住区道路规划 普遍采用的 “通而不畅” 设计原则, 理论上有很大进步, 而且从减少穿越交通的角度, 这一 原则也是合理的, 但由于实践中一般忽视支路之间的衔接, 以致产生过多的错位交叉, 造成 城市道路网络 “不通不畅”，使各种交通流都向干路网络汇集，还特别不利于公交路线在居 住区内的组织。

\section{2常年拓宽修路与居住区建设模式互为因果的恶性循环}

拓宽道路后生活性道路逐渐演变成交通性干路, 由于原有道路交叉口存在, 目前的方法 为了解决交通的顺畅, 在路中心增加护栏隔离带, 生活性的进出越发费劲起来。由于道路的 拓宽中小学校的主要出入口就直接面向城市 “交通性的干路” 早晚高峰接送孩子, 路边停车, 就成为混乱不堪的局面, 城市循环成为一场灾难。这种现象在大城市中每天上演, 是路不够 宽吗? 作者认为是城市的脑血栓, 城市的微循环系统被城市用地单元吞噬了。与此同时, 目 前的居住小区（基本用地单元）内部道路多为闲置，惨淡，荒芜，没有人气的景象使然。

“大马路” 道路结构:

现代主义的 “大马路” 道路结构是一种畸形的城市结构。它好像是网状道路结构, 但是 道路密度低, 就好像将正常的网状道路中每五条道路去掉四条, 同时道路宽度大。它有时又 像是树状结构, 只不过没有地方街道, 只剩下次干道和主干道。从表面看, 它与网状结构很 相似, 但实际上它已丧失了网状道路的基本特点, 即不具备出行路径的多种选择, 因为道路 间距过大。

“大马路”与 “住宅小区” 互为因果。现代主义的大马路传到中国后, 情况进一步恶化。 道路密度又下降了许多, 道路间距进一步拉大, 城市网络惨遭破坏, 特别是 “住宅小区” 的 大量建设，使得 “大马路”无法避免。

柯布西埃在提出了 “公园中的高楼” 的城市形态的同时，还提出 “大马路” ，它们不但 是现代主义城市形态的不可分割的组成部分, 而且两者是缺一不可。首先 “住宅小区” 的规 模都很大, 其次住宅小区内的道路完全独立于城市道路系统之外, 两者完全不衔接。于是城 市规划道路必须环绕其外, 这就使城市道路的间距变得非常大。这里我们假设一个40公顷的 
正方形 “住宅小区” 其容积率平均为 1.5 , 那它的红线内的面积就大约是 $520 \mathrm{~m} \times 520 \mathrm{~m}$, 再加 上红线后退, 由此形成环绕其外的城市路网就差不多是700 m。因此,一旦规划了 “住宅小区” 这种住宅形式，那必然产生 “大马路”。

反过来, 一旦城市道路网的密度降低, 道路就必然要做宽, 因为只有这样才能容纳增长 的交通量, 结果是形成的街区也变得无比巨大, 要在如此大的街区内布置住宅区, 那 “住宅 区” 就是必然的结果。也就是说低密度的城市道路网和 “大马路” , 必然产生 “住宅区”（这 是目前现实中的普遍做法）。

于是 “住宅区”与城市低密度道路网的 “大马路” 就形成了互为因果的关系。相距少则 400-500 m, 多则上千米甚至几千米。道路的宽度往往与道路间距成正比, 即道路网的间距越 大, 道路的宽度也越宽。原因是随着道路间距的加大, 道路网密度也随之降低, 而每一条道 路所承担的交通量则相应加大, 于是道路也必须增加宽度以适应交通量的增加, 这样 “大马 路” 就出现了。同样, 一旦出现了 “大马路” , 道路间距也必然加大, 原因是为了更充分地 利用道路资源, 人们不可能将两条 “大马路” 相距很近地布置在一起（永远也看不到相距100 $\mathrm{m}$ 的两条 $100 \mathrm{~m}$ 宽的大马路）。可以说, “大马路” 与低密度道路网是互为因果关系, 即有大 马路, 则城市道路网密度必然降低; 而一旦城市道路网密度降低, 则必然出现 “大马路”。

\section{4城市非保护类街区有机更新与城市用地单元重构}

多年来的城市公园开放，拆除围墙，对真正城市公共空间的开放有划时代的意义，公园 的利用效率提高了, 体现了公平的人文关怀序幕。公园的开放, 体现了城市开敞空间的公共 性和融合性的作用。同时也体现了城市资源共享的开端。而今天的居住小区等级化的, 封闭 化的结果在市场力的作用下更是强化与共享经济时代的需求背离。

\section{1用地基本单元规模调整-社区走向开放}

争取居住区内部道路的公共化潜力，使封闭地块内部的次干道和城市支路向城市空间开 放, 形成网络化的空间组团格局。居住级, 小区级道路路面也应在可能的情况下拓宽并向城 市开放。

目前我国的微观土地利用单元强调各项设施的功能划分，在布局上各成体系，很难做到 功能的复合交叉。通常公共活动设施在小区内居中布局, 小区道路单纯担负小区的交通功能, 商业设施设置于小区的入口以及小区外围沿街的裙房。居住小区机械的组织结构所造成的各 种功能彼此的不交叉。然而在缩小居住小区的规模后, 在同一个城市干道划分出的大地块中, 可能包容几个封闭的组团, 并可能在地块中插入其他职能空间, 有可能就此改善居住空间的 组织结构。具体方式是将居住小区的各项配套服务设施从居住小区中分离抽取出来, 置于几 个封闭组团的交界线形成的道路上(街道), 将这种道路建设成步行街或符合人的尺度的人车 混流的小路, 改变其单纯的交通功能, 使复合交通、生产设施、商业设施等多重功能, 在道 路上形成交往、购物、休息、饮食、观赏、儿童游戏等活动, 并有可能形成密集人流的聚集, 并以此改善居住空间的生活气氛。同时利用各小区间规划中预留的弹性空间，允许某些功能 以及功能所需空间的自发形成或调整，以引发规划无从设计的空间细节和自发形成的城市肌 理, 从而在改善住宅组织结构、重组各功能设施之间的关系的同时, 逐步恢复传统街区的多 元化和多层次, 在这些小街中为社会各阶层提供需要的各种类型生活空间共享。

\section{2路网更新与用地开发单元规模:}

改居住区--居住小区一居住组团为开敞居住区---封闭组团模式以城市次干道取代居住区 级道路，城市支路取代居住小区级道路，以城市支路组织生活次街。

虽然城市路网与住宅区用地开发单元规模以及生活次街的建立并不存在因果关系,但是 一个由城市路网划分形成的恰当的住宅区用地规模和层次完善的城市街道系统对住区邻里环 
境和城市人文环境的形成无疑是有利的。忽视系统完善的生活次街的建立, 直接造成了目前城 市住宅区用地开发单元规模过大、城市道路交通拥挤的现代城市问题,而更为重要的是传统居 住人文环境的丧失。所以,对生活住区的生活次街的营造,对现有城市路网进一步划分,完善城 市交通组织体系和城市生活街道系统, 是重新组建城市住区宜人的人文环境的关键所在。建立 适宜的居住型街道系统, 使住宅区用地开发单元规模既便于组织住宅区的开发, 有利于建立与 发展宜人的人文环境, 有利于提供社区住户开展各类交往活动的可达性与系统性兼备的场所, 同时也可以分解城市干道的生活性交通。

针对城市总体规划中普遍采用的500-700米的城市路网间距,城市分区规划或城市控制性 详细规划阶段可以在总体规划确定的生活居住区(用地)中将城市路网中平行或交叉覆盖一个 200-300米间距的生活居住型次要街道网络。

同时也将住宅区用地规模由原来的10-20公顷缩小到4公顷左右,居住人口大约在 1500 人左 右。这样一个生活次街网络的设立以及由此形成的较小的住宅用地开发单元规模带来的结果 是:原先概念上的住宅组团因相对独立而被强化,住宅院落的空间被明确地限定,邻里交往的场 所感被加强,互助型邻里关系形成的可能性更多了;原先意义上的 “小区级道路” 由于可达性增 强,生活服务设施的配置也因为市场的竞争和调节因素而合理化、特色化, 吸引力的增加使较大 范围内的居民的接触和交往成为可能, 邻里间相识和认同的机会也随之增加。

同时采取 “交通管理导向 “的思路对路网结构划分形成开敞社区封闭组团的道路空间模式。 避免出现 “交通性道路断面宽, 生活性道路断面窄” 的固定模式, 以更好的适应公交城市鼓 励步行和公交出行的特点。

在对城市路网进行再划分,在微观土地利用单元内建立起联系与组织住区交往活动的 “生 活次街”的同时,还应该对住宅区服务设施进行重组性的考虑。

当 “生活次街” 设立后,根据住户的实际需求,可以把居住区两类公共服务设施进行重新组 合,一些服务设施可以从目前的居住区和居住小区中划分出来独立考虑, 设置在生活次街上, 比 如非盈利性设施中的中小学、医学、邮局、中心公园、物业管理中心、住区综合管理中心, 以 及盈利性设施中的大中型超市、住区商业中心、银行、小型便民超市等。

这些设施可以在统一规划的要求下由各房地产开发商(土地投资者和使用者)联合营建,也 可以由各房地产开发商出资由居住区开发公司(土地管理者)统一组织营建,这中间还需要规划 实施管理体制的调整和配合。居住区和居住小区的生活服务设施沿 “生活次街” 布置,处在城 市半公共空间内,具有良好的可达性,周围住宅区内住户是它的基本客户,它可以提供给住区住 户进行各类交往活动的可能,从而使城市街道(主要指 “生活次街” )的交往功能得以复兴,社区 适居宜人的人文环境也随之确立起来。其他的公共服务设施则分散在相对独立的、较小的住 宅区内。（如图5）

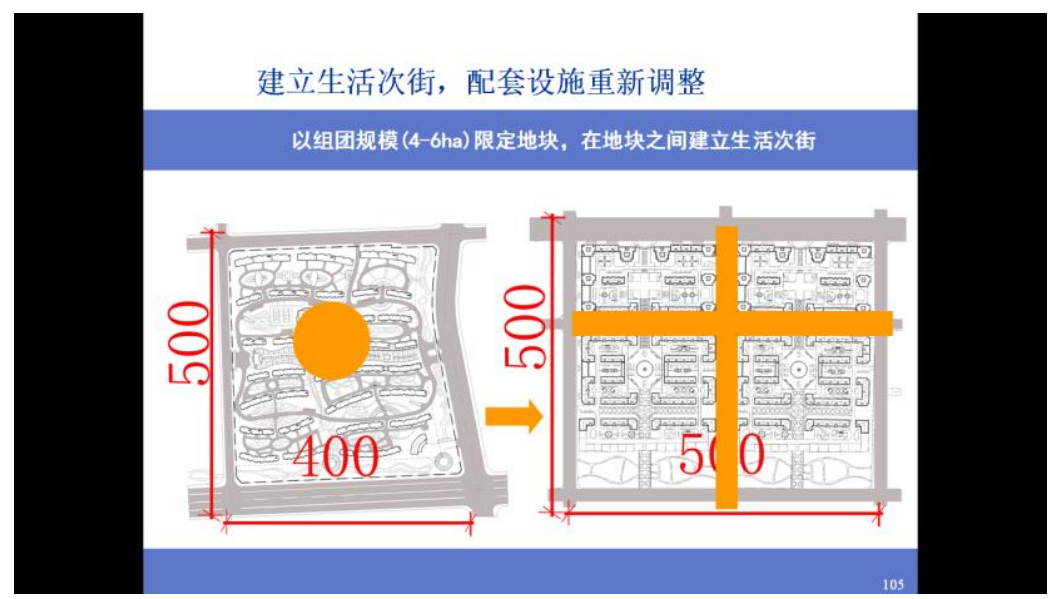

图5 用地开发单元模式对比 
脱离了一些公共生活服务设施特别是非盈利性公共服务设施的开发建设活动,不但能减小 开发成本和风险,降低商品房的价格,更能使各独立开发商把重点放到住宅区品质的提高上。同 时,各类公共服务设施由于 “走出了原先的围墙”, 而得以增大服务规模,增多服务内容,提高服 务品质,使围绕住宅的街道生活得以复兴与发展,使住宅区的认知性、聚合性得以加强同时增加 社会就业。现代城市的住宅区不应是小而全或大而全的居住生活单位,各种公共服务设施应该 整体优化组合,扩大服务范围。减小目前住宅区单元规模,建立城市生活次街系统,把一些公共 服务设施从目前的住宅区中分离出来放到城市的 “生活次街” 中去组织,简化住宅区的内部职 能,丰富城市街道生活的意义,有助于组建社区良好人文环境、提高社区生活品质、优化组合各 种公共服务设施,有助于营造具有互补性、异质性、可达性、各类空间和用地合理布局的居住 生活地域。

\section{3服务设施重组与街道生活复兴}

社区或街区内的道路应该相互连接成网络，这样可以提供更多的出行路线的选择，从而 疏散交通流量。现代主义将道路视为机动车的渠道, “大马路” 的出现以致最终成为城市的 主宰，从而失去了自古以来就有的街道定义社区的关键作用。“住宅小区” 配之以大马路将 几千年来人类城市文化的灵魂 “街道” 彻底消灭了, 我们看到的要么是车流滚滚的宽广的大 马路, 要么是小区内部楼前楼后的小道。“宽马路” 不仅仅是城市道路宽大, 它还代表了一 种城市形态, 这就是城市的一切都背离街道, 而不是积极的面向街道。建筑的正面背离街道, 结果是街道缺乏可以交流的内容, 人们步行面对的是没有内容的巨大墙壁, 使步行环境丧失, 街道变成了渠道。此外, 大马路还造成超大的城市街区, 使步行不愉快。当然, 公共交通的 距离也加大, 使得居民使用不便。完全为机动车服务的现代主义大马路的大量出现, 使得在 城市中步行非常不愉快。而一旦步行环境丧失，则街道文化不复存在。

街道的形式将极大的影响整个社区的特点和质量, 新都市主义街的重要性提高到了前所 未有的高度, 彻底抛弃了现代主义将 “街” 仅作为交通通道的做法, 强调街的多功能效应, 即它是人们进行社区交往的场所, 是儿童玩要的地方, 是步和自行车交通的通道, 还是各类 住宅的人口。将汽车停在街道上, 认为这样不但可以在人行道和车行道之间创造一种缓冲, 而且可以鼓励步行活动和创造活跃的街道气氛。实际上这反映人们对街道看法根本转变。开 敞社区可以组织城市公交深入社区内部, 便利便突显出来。

\section{4组团封闭的意义}

邻里是带有集体性家庭的基地, 空间要靠围合产生。居民在各自得住宅内不会感到舒适, 而组团内有一块公共空间, 切不能太大, 而住宅彼此挨的很近邻里会给人以安全感和温暖感。 这个邻里公共空间是一种场所尺度（100 米范围内）普遍认为是人心里层面感受的尺度。

要构建邻里中心，住宅在要有自己的私密性，同时在尊重私密性的前提下，有相互间的 交往接触与支持。邻里关系意味着各户都是邻里的一个成员, 参与邻里的一些共同活动, 邻 里要有一定的边界, 在边界内有一定的共同利益, 也有一定的归属感和认同感。一般情况下 5-12栋住宅在形成邻里关系上有很好的效果, 一旦超出这样的尺度, 邻里关系就会变弱。另 外组团内不能过于密集和自给自足, 否则就会排除较大的社区, 组团与组团之间的关系上必 须有交叉和重叠这个重叠部分就是边缘的公共空间和公共设施。

要实现社区群体间的有效交往和认同感，必须有明确的领域范围和标识。空间性能使人 们获得归属感, 场所性会给人认同感, 领域性会给人分享的社会感。这就形成了符合人性尺 度的, 封闭与开敞的空间需求。而组团的封闭可以由街道上的裙房, 小围墙, 绿化带以及组 团入口及出口的小门来协作封闭，实施性封闭和心理作用下的封闭共同完成。 


\section{5瓦解居住小区模式, 微社会空间由权力空间走向权利空间}

众所周知 “权力”是排他性的封闭的，“权利”空间是分享性的开放的，权益性的。我们 可以看到中国城市建设的历史脉络由 3 个力决定, 政治力的等级化空间一单位大院，市场力的 等级空间一居住区居住小区, 社会力的空间一公平公正的以人群定义的嵌套递进的分享型空 间的社会尺度单元。而社会力的空间结果就是权利空间的营造, 这种空间是半网络叠加, 透 明性的和重叠性的。人们生活在空间中即属于小组群体，也属于大组全体。权力空间被弱化， 权利空间被增强。因此社会基础设施和公共设施被完全公共化共享，居住小区模式被重新解 构和重构, 形成完全意义上的社会化社区。作为领域感很强的等级化的居住小区空间不复存 在, 以节约生活成本，提高效率的分享空间形成，等级化的 “我们的空间” 和他们的空间被 模糊化, 以兴趣, 爱好, 而非阶级, 收入为标杆的社会功能空间得以出现。以 “社群” 为目 标的工作, 生活, 娱乐需求, 在共享经济条件下得以实现。趋于平等的社会结构通过新的城 市空间释放。闲置的时间碎片和空间碎片也同时释放与共享。

\section{5 社区开敞与组团封闭对城市发展的意义及实施}

封闭组团有增强邻里的归属感认同感强化交往单元。营造共融空间, 强化边界作用。由 物业管理走向邻里自制方向变化, 降低了管理成本。社区开敞有利于公共闲置空间充分分享 给社会 提高公共空间的使用效率和共享力。同时分解城市干路交通压力, 稀释疏通城市毛细 血管, 增加城市支路网络。共享社会停车设置, 稀释干路路边停车的混乱与干扰乱像。争强 社区活力, 创造具有生活乐趣的街道。重新界定用地单元的规模, 以组团规模（4-6ha）用地 单元组建新的居住模式, 对于城市建设密集区的存量已建小区，规模在10公顷以上的居住小 区进行变更，打破居住小区的建设模式，开放居住原小区级道路为社会道路一生活次街。瓦 解居住小区的门禁, 以居住组团为单位进行封闭门禁。小区级核心绿地及开敞空间向社会开 放, 配建中学小学运动场地择时对公众开放, 资源共享。限制城市主次干路及以上级别的路 边停车, 适当拓宽原居住小区级道路, 增加该路路边停车带, 为社会共享。

\section{6结论:}

当前西方住区建设早已经过了大规模开发阶段,逐步走向小规模、渐进式的住区开发模 式。而我国正处于社会经济的转型时期,采取大规模开发方式建设住区, 以适应人们迅速增长的 对住房数量和质量的需求,也是现实的选择。但是大规模开发不应等同于规模无限制的大型化, 对规模仍然需进行合理的调控, 使之成为真正的城市型住区,并融入城市的有序的渐进的发展 之中。总之城市基本地块单元不应该是居住小区规模, 而应该是居住组团的用地规模。城市 存量土地的更新与规划要一改居住小区的模式惯性思维, 建立以共享资源为目标的开敞社区 封闭组团模式。

\section{致谢}

辽宁省教育厅人文社科课题资助项目《城市公共空间建设问题及形态对策研究》的阶段 性成果。项目编号: L201647

\section{References}

[1] National urban planning system management committee .Principles of urban planning,[M].Beijing. China Planning Press, 2002.

[2] Jeremy. Rifkin. The Empathic civilization: The Race to Global Consciousness In a world in Crisis $[\mathrm{M}], 2010$. 
[3] Christopher Alexander. A City is Not a Tree [M].1965.

[4] Wang.Yuwei. Chinese unit-The Hybrid of Economic and Political Power[J].Across Architecture and Urban Flux ,vol.41 ,2015(2).

[5] Piper Gaubatz. New Public Space in Urban China :Fewer Walls, More Malls in Beijing shanghai and Xining[J]. China Perspectives,pp.72-83,2008(4).

[6] Gao.Huijie. Residential cluster and neighborhood space[J]. Construction \& Design for Engineering, pp.16-18,2005(7). 